Research Article

\title{
Synergistic Hepatoprotective Interaction between $\alpha$ - Tocopherol and Ascorbic Acid on Paracetamol Induced Liver Damage in Rats
}

Saidul Islam Khan ${ }^{1 *}$, Mahmuda Begum², Rama Chowdhury³, Md. Mizanur Rahman ${ }^{4}$, Muhammad Asaduzzaman ${ }^{5 *}$

1 Department of Physiology, International Medical College, Tongi, Gazipur, Bangladesh. e-mail: dr_sikhan@live.com

2 Department of Physiology, Sir Salimullah Medical College, Dhaka, Bangladesh. e-mail: mahmudacme@yahoo.com

3 Department of Physiology, Sir Salimullah Medical College, Dhaka, Bangladesh. e-mail: mithucy88@gmail.com

4 Assistant Professor, Department of Physiology, Enam Medical College, Savar, Dhaka, Bangladesh. e-mail: mizandr001@gmail.com

5 Research fellow, Centre for Global Health, University of Oslo, Norway. e-mail: muhammad.asaduzzaman@medisin.uio.no

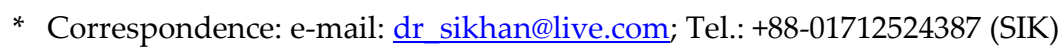
e-mail: muhammad.asaduzzaman@medisin.uio.no; Tel.: +47-96835658 (MA) 


\begin{abstract}
:
Background and objectives: The hepatoprotective activity of vitamin $\mathrm{E}$ and $\mathrm{C}$ is evident due to their ability of modulating the antioxidant pathway. In this study, we have evaluated the effects of $\alpha$-tocopherol and ascorbic acid on paracetamol induced liver damage with offsetting various levels of drug treatment following an in vivo experimental protocol on Wistar albino male rats.

Materials and Methods: The level of lipid peroxidation as well as histological examination of liver tissues were observed among 50 Wistar albino male rats to evaluate hepatoprotective effect of $\alpha$-tocopherol and ascorbic acid on hepatocytes. The experiment was divided into 5 groups (10 rats in each group)- Basal control group (Group-I, with propylene glycol), Paracetamol treated control group (Group -II), $\alpha$-tocopherol pretreated \& paracetamol treated group (Group -III), Ascorbic acid pretreated \& paracetamol treated group (Group -IV) and Ascorbic acid pretreated \& paracetamol treated group (Group -IV).
\end{abstract}

Results: The mean ( \pm SD) Malondialdehyde (MDA) concentration were significantly reduced in $\alpha$-tocopherol pretreated and paracetamol treated group $(\mathrm{P}<0.001)$, Ascorbic acid pretreated and paracetamol treated group $(\mathrm{P} \leq 0.05)$ and combined $\alpha$-tocopherol with ascorbic acid pretreated \& paracetamol treated group $(\mathrm{P}<0.001)$. Statistically significant differences in histological findings of rat liver were observed in paracetamol treated control group $(\mathrm{P}<0.001)$, ascorbic acid pretreated and paracetamol treated group $(\mathrm{P}<0.001)$. The serum alanine aminotransferase (ALT) level was also significantly higher in paracetamol treated group ( $<<0.001), \alpha-$ tocopherol pretreated plus paracetamol treated group $(\mathrm{P} \leq 0.05)$ and in ascorbic acid pretreated plus paracetamol treated group $(\mathrm{P}<0.001)$.

Conclusion: The combined pretreatment of $\alpha$-tocopherol \& ascorbic acid have better hepatoprotective effects than $\alpha$-tocopherol or ascorbic acid alone against paracetamol induced liver damage. The decrement of free radicals produced by vitamin $\mathrm{E}$ could be a better hepatoprotective antioxidant than vitamin $\mathrm{C}$ in paracetamol induced toxicity.

Keywords: Hepatoprotective, ascorbic acid, $\alpha$-tocopherol, paracetamol, ALT, MDA, Histology. 


\section{Introduction}

Liver disease is a major cause of morbidity and mortality, globally. The continuous exposure of the liver to some factors such as viruses, alcohol, fat, and bio transformed metabolites can cause hepatic injury[1]. Besides, as the major drug metabolizing and detoxifying organ in the body, the liver is subject to potential damage from enormous array of pharmaceuticals and environmental chemicals. Severe acute liver disease encountered in clinical practice may lead to fulminant or acute liver failure, mostly due to drug or toxin induced hepatic injury or viral hepatitis [2],[3]. Hepatotoxicity caused by drugs, in particular idiosyncratic reactions, is a major challenge to the pharmaceutical industry and physicians[4].

Incidence of drug induced liver injury in the general population ranged from 7 to 13 per 100,000 with a significant mortality rate of about 10 percent[5]. Overdose of acetaminophen (paracetamol) has affected the patients for decades and involves the cornerstone metabolic pathways which takes place in the microsomes within hepatocytes[6]. Although paracetamol generally considered a safe as an antipyretic and analgesic drug, it may cause death through overdose, idiopathic reaction or synergism with alcoholic liver disease[7]. Acute liver failure caused by acetaminophen has been attributed to the metabolic activation of acetaminophen to a toxic metabolite, N-acetyl-pbenzoquinone imine (NAPQI) in the liver by cytochrome p450 isoenzymes especially CYP2E1 and NAPQI depletes liver glutathione by inducing oxidative stress [8]. As a result, over production of reactive oxygen species (ROS) such as superoxide radicals, hydrogen radicals and hydroxyl radicals happens. Excess levels of ROS can attack biological molecules such as DNA, protein, phospholipids, which leads to lipid peroxidation and depletion of antioxidant enzymes such as superoxide dismutase (SOD), catalase (CAT) and glutathione peroxidase (GPx)[9,10]. It also binds to vital cellular and mitochondrial proteins leading to cellular necrosis, and activates cells of the immune system leading to the release of proinflammatory cytokines[8]. On the basis of these facts, antioxidant therapy alone or in combination with other pharmacological strategies appears as the most reasonable treatment of a variety of liver diseases[11]. Vitamin E is an antioxidant which has its capacity of either reducing the harmful effect of free radicals by preventing the oxidation of 
polyunsaturated fatty acid in the cell membrane[12] or restoring the normal lipid profile and to reduce the oxidative modification of LDL that has been distributed by paracetamol [13].

There are about eight naturally occurring tocopherols with vitamin E activity. Among these, $\alpha$ tocopherol is considered to be the most important tocopherol and it has been reported to constitute about $90 \%$ of the tocopherols in animal tissues and displays the greatest biological activity in bioassay systems[14]. It is a potent chain breaking antioxidant that inhibits the production of reactive oxygen species molecules when fat undergoes oxidation and during the propagation of free radical reactions[15]. In developing countries, there is a greater risk for deficiency of vitamin E due to limited intake of vitamin and higher prevalence of oxidative stressors which is characterized by recurrent abortion, degenerative changes in spinal cord, peripheral neuropathy, ataxia, and haemolytic anemia etc.[16].

On the other hand vitamin $\mathrm{C}$ or ascorbic acid is a water soluble versatile vitamin and a strong reducing agent and antioxidant. It is a cofactor in reactions catalyzed by Copper dependent monooxygenases and has a great role in bone formation, Iron and haemoglobin metabolism, folic acid metabolism, synthesis of hormones, immunological function etc. [17]. Although many vertebrates can synthesize ascorbic acid or vitamin C[18], vegetables, citrus fruits, non-citrus fruits, green leafy vegetables, juices are the human Source of vitamin C [19]. Surprisingly,the increased sensitivity to oxidative stress is largely reversed when glutathionedepleted cells are preloaded with ascorbic acid by exposure to dehydroascorbic acid. Therefore, vitamin $\mathrm{C}$ is an important independent antioxidant in protecting cells against death from oxidative stress [20]. Based on these scientific evidences, we argue that both vitamin $\mathrm{E}$ and $\mathrm{C}$ have preventive actions on paracetamol induced hepatotoxicity in albino rats through their potential anti-oxidant mechanism of hepatoprotective action[21]. Our resent study has been designed to evaluate the effects of $\alpha$-tocopherol and ascorbic acid on paracetamol induced liver damage with offsetting various levels of drug treatment following an in vivo experimental protocol on Wistar albino male rats. 


\section{Materials and Methods}

\subsection{Experimental animals}

This experimental study was conducted in the Department of Physiology, Sir Salimullah Medical College, Dhaka, from 1st January 2017 to 31st December 2017. All experiments were approved by the Institutional Ethics Committee (IEC) of Sir Salimullah Medical College (SSMC), Dhaka (approval number-SSMC/Dhaka/2017/35) and animal care were performed according to the guidelines set in the 'Manual for Care and Use of Laboratory Animals' by the Animal Experimentation Ethics Committee (AEEC) of the International Centre for Diarrhoeal Disease Research, Bangladesh (icddr,b 2002).

Fifty (50) apparently healthy Wister albino male rats, weighing 160 to 200 gm were obtained from animal house of Department of Pharmacy, Jahangir Nagar University, Savar, Dhaka. All the rats were kept in a well-ventilated animal house where they were acclimatized for 10 days prior to intervention at $28 \pm 2 \mathrm{oC}$ room temperature under 12 hours light/12 hours dark cycle [22-24]. All the rats had free access to standard laboratory food and cooled boiled water. They were kept there for a period of ten (10) consecutive days for environmental acclimatization, prior to the experiment[25]. After 10 days of acclimatization, the total study period was 30 consecutive days. At the beginning of the study period (day 1) initial body weight of all the rats were measured and at the end of the study period after measuring the final body weight, all the rats were anesthetized with the help of chloroform (30\%) [26,27] sacrificed on day 31 (24 hours after last dose of paracetamol administration).

\subsection{Materials and chemicals}

$\alpha$-tocopherol (Drug International Ltd, Bangladesh) was obtained in liquid form. Ascorbic acid (Sigma-Aldrich, USA) and paracetamol (acetaminophen) (Amico Laboratories Ltd, Bangladesh) were obtained in granular form.

\subsection{Preparation of paracetamol solution}

$1 \mathrm{~g}$ of paracetamol (active ingredient) was dissolved in $9 \mathrm{ml}$ of propylene glycol. After thorough mixture a homogenous solution was obtained, giving a strength of $111.11 \mathrm{mg}$ of paracetamol per $\mathrm{ml}$ of solution [28]. 


\subsection{Preparation of $\alpha$-tocopherol solution}

Four E-CAP $200 \mathrm{mg}$ capsule was cut and uncapsulated the liquid material to make $1 \mathrm{ml} \alpha$-tocopherol solution which was taken into disposable syringe. So, 1 ml solution contained $800 \mathrm{mg}$ (200 mg/ capsule x 4) of $\alpha$-tocopherol.

\subsection{Preparation of ascorbic acid solution}

$1 \mathrm{~g}$ of ascorbic acid powder was dissolved in $20 \mathrm{ml}$ of distilled water. A thorough mixture a homogenous solution was obtained, giving a strength of 50 of ascorbic acid per ml of solution.

\subsection{Preparation of liver for histological examination}

After 24 hours of last dose of paracetamol administration, all the rats were anesthetized with the help of chloroform (30\%) and then sacrificed. Liver was removed from each rat and washed in ice-cold saline, then the weight was measured by electric balance analyzer. A small part of liver tissue (approximately $500 \mathrm{mg}$ ) was cut and taken in foil paper with proper labeling and placed on an ice bath and was kept in deep freeze until homogenized. The rest of the portion was preserved and fixed in $10 \%$ formalin solution for subsequent histological processing. To find out the histopathological changes of liver tissue, histological slides were prepared, observed under the microscope and photomicrographs were taken by using standard laboratory procedure in the department of Pathology, Sir Salimullah Medical College, Dhaka, Bangladesh.

\subsection{In Vivo Experimental Protocol}

Basal control group (Group I) treated with propylene glycol, $2 \mathrm{ml} / \mathrm{kg}$ [29] b.w. orally on day 28,29 and 30.Whereas the other groups were treated with $\alpha$-tocopherol, $100 \mathrm{mg} / \mathrm{kg}$ [21,30] b.w. and ascorbic acid, $200 \mathrm{mg} / \mathrm{kg}$ [21,30] b.w. for 30 days respectively (Group III, Group IV). In addition, Group V was orally treated with $\alpha$-tocopherol $100 \mathrm{mg} / \mathrm{kg}$ b.w. plus ascorbic acid $200 \mathrm{mg} / \mathrm{kg}[21,30]$ b.w. for 30 days.

Groups 2-5 were given a toxic dose of paracetamol, $1500 \mathrm{mg} / \mathrm{kg}$ b.w. on 28,29 and 30 day to observe hepatotoxicity [27]. 


\subsection{Determination of intracellular lipid peroxidation (LPO)}

$100 \mu \mathrm{l}$ of $8.1 \%$ sodium dodecyl sulfate (SDS), $2 \mathrm{ml} \mathrm{4 \%}$ thiobarbituric acid (TBA) in $20 \%$ acetic acid (AA) and $200 \mu \mathrm{l}$ distilled water $(\mathrm{D} / \mathrm{W})$ were taken in a test tube. To this mixture, $100 \mu \mathrm{l}$ of liver homogenate was added. Then this mixture was heated in boiling water for 60 minutes. After cooling in room temperature, $3 \mathrm{ml}$ of butanol \& pyridine mixture was added to it. After vigorous shaking for 30 minutes in a mechanical shaker, the mixture was centrifuged at $5000 \mathrm{rpm}$ for 15 minutes. The supernatant was separated and the intensity of pink color was read against standard $(1,1,3$ tetrahydroxypropane) in the spectrophotometer at wavelength $532 \mathrm{~nm}$. The level of lipid peroxidation was expressed as nmoles of MDA / mg protein.

\subsection{Data analysis}

Numerical data were presented as mean \pm SD. Statistical analysis was done by one way ANOVA test. Post hoc Bonferroni test was performed to compare between groups and Fisher's exact test was done for histological analysis. Paired' $\mathrm{t}^{\prime}$ test was also done. $\mathrm{P}$ value $\leq 0.05$ was considered statistically significant. Statistical analyses were done by using Statistical Package of Social Science (SPSS). Windows version 22.

\section{Results}

\subsection{Biochemical analysis}

Alanine aminotransferase (ALT) was measured in Wroblewski and LaDue principle and Backman Culter AU 680 system. The serum ALT level (Figure-1) was significantly increased in paracetamol treated group $(\mathrm{P}<0.001), \alpha$-tocopherol pretreated plus paracetamol treated group $(\mathrm{P} \leq 0.05)$ and also in ascorbic acid pretreated plus paracetamol treated $(\mathrm{P}<0.001)$ than that of baseline control group. However, This level was significantly decreased in $\alpha$-tocopherol pretreated plus paracetamol treated $(\mathrm{P}<0.001)$, ascorbic acid pretreated plus paracetamol treated $(\mathrm{P}<0.01)$ as well as in combined $\alpha$-tocopherol with ascorbic acid pretreated plus paracetamol treated $(\mathrm{P}<0.001)$ in comparison to that of paracetamol treated group. 


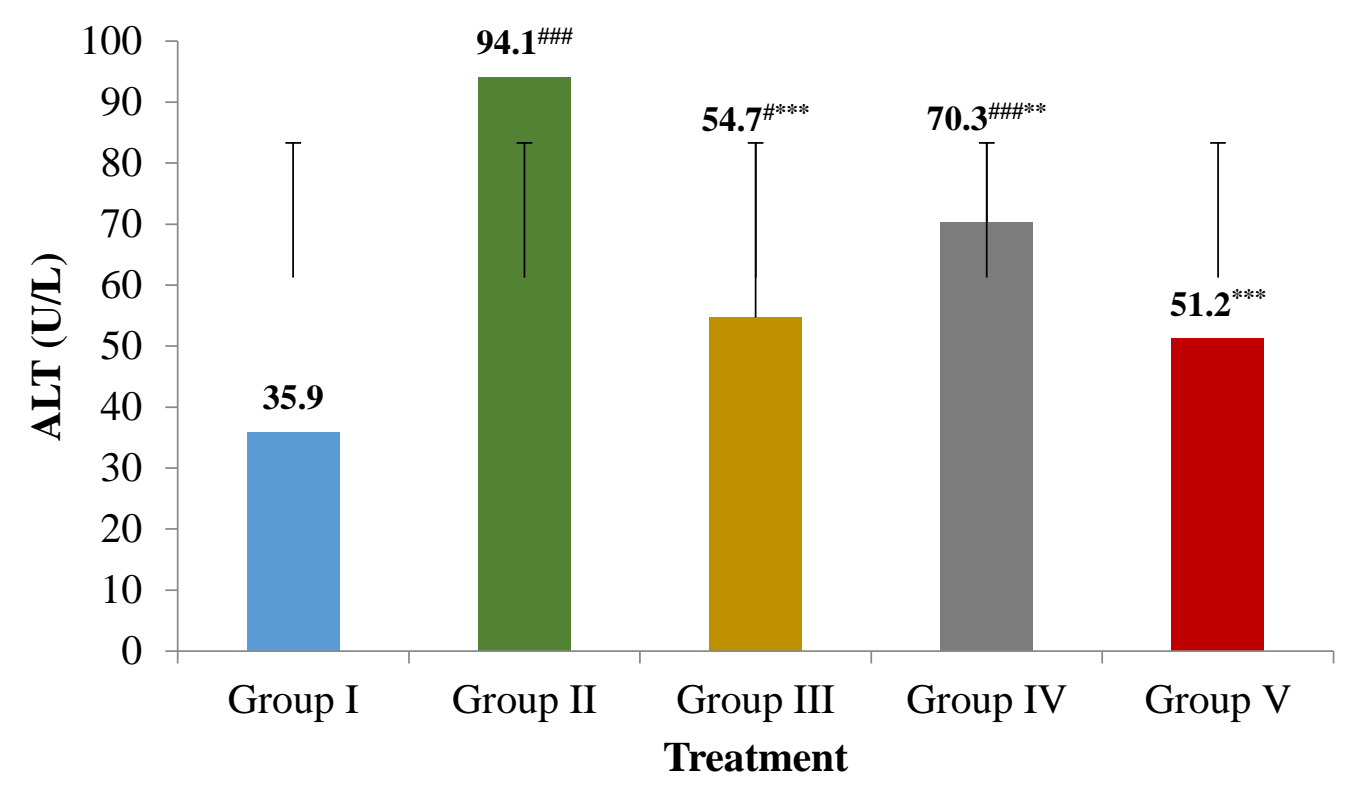

Figure 1: Serum alanine aminotransferase (ALT) level in different groups of rats $(n=50)$. Each data bar represents the Mean $\pm \mathrm{SD}, \# \# \mathrm{p}<0.001 \& \# \mathrm{p} \leq 0.05$ when compared with Group I (control); ${ }^{* * *} \mathrm{p}<0.001$ and ${ }^{* *} \mathrm{p}<0.01$ when compared with Group II (paracetamol treated). n=number; Group-I= Baseline control group; Group-II= Paracetamol treated group; Group-III $=\alpha$-tocopherol pretreated plus paracetamol treated group; Group-IV= Ascorbic acid pretreated plus paracetamol treated group; Group-V= Combined $\alpha$-tocopherol with ascorbic acid pretreated plus paracetamol treated group.

On the other hand, MDA concentration in liver tissue significantly decreased in $\alpha$-tocopherol pretreated \& paracetamol treated group $(\mathrm{P}<0.001)$, Ascorbic acid pretreated \& paracetamol treated group $(\mathrm{P} \leq 0.05)$ and combined $\alpha$-tocopherol with ascorbic acid pretreated \& paracetamol treated group $(\mathrm{P}<0.001)$ in comparison to that of paracetamol treated control group (Table-1).

Table 1: Malondialdehyde (MDA) concentration in liver in different groups of rats $(\mathrm{N}=50)$.

\begin{tabular}{cc} 
Groups & MDA \\
& $(\mathrm{nmol} / \mathrm{mg}$ protein $)$ \\
\hline I $(\mathrm{n}=10)$ & $3.93 \pm 2.31$ \\
$\mathrm{II} \quad(\mathrm{n}=10)$ & $10.23 \pm 1.53 \# \# \#$ \\
& \\
III $(\mathrm{n}=10)$ & $5.23 \pm 2.16^{* * *}$
\end{tabular}



IV $(\mathrm{n}=10)$
$7.31 \pm 1.89 \# \# *$
$\mathrm{V} \quad(\mathrm{n}=10)$
$4.90 \pm 1.15^{* * *}$

Each data bar represents the Mean \pm SD, \#\#\# $<0.001 \&$ \& \#p<0.01 when compared with Group I (control); ${ }^{* * *} \mathrm{p}<0.001$ and ${ }^{*} \mathrm{p} \leq 0.05$ when compared with Group II (paracetamol treated). $\mathrm{n}=$ number; Group-I= Baseline control group; Group-II= Paracetamol treated group; Group-III= $\alpha$-tocopherol pretreated \& paracetamol treated group; Group-IV= Ascorbic acid pretreated \& paracetamol treated group; Group-V= Combined $\alpha$-tocopherol with ascorbic acid pretreated \& paracetamol treated group.

\subsection{Histological findings}

The distribution of histological changes in liver of the rats for different groups has been shown in Table 2. Histopathological sections of liver in baseline control group rats showed well preserved hepatic lobule, central vein, hepatocytes, portal tract and hepatic sinusoids (Figure-2,3), whereas, moderate histological changes with presence of fatty change, ballooning degeneration, infiltration of lymphocytes and centrilobular necrosis were noted in paracetamol treated group (Figure-4,5).

Table 2: Distribution of rats by histological changes in liver $(\mathrm{N}=50)$

Histological findings

\begin{tabular}{ccc} 
Groups & Normal & Abnormal \\
& $\mathrm{n}(\%)$ & $\mathrm{n}(\%)$ \\
\hline I $(\mathrm{n}=10)$ & $10(100.0)$ & $0(0)$ \\
II $(\mathrm{n}=10)$ & $0(0)$ & $10(100.0)$ \\
III $(\mathrm{n}=10)$ & $7(70)$ & $3(30)$ \\
IV $(\mathrm{n}=10)$ & $5(50)$ & $5(50)$ \\
V $(\mathrm{n}=10)$ & $8(80)$ & $2(20)$
\end{tabular}

Each data bar represents the Mean $\pm \mathrm{SD}, \# \# \# \mathrm{p}<0.001$ when compared with Group I (control); ${ }^{* *} \mathrm{p}<0.01$ and ${ }^{*} \mathrm{p} \leq 0.05$ when compared with Group II (paracetamol treated). $n=$ number; Group-I= Baseline control group; Group-II= Paracetamol treated group; Group-III $=\alpha$-tocopherol pretreated \& 
paracetamol treated group; Group-IV= Ascorbic acid pretreated \& paracetamol treated group; Group-V $=$ Combined $\alpha$-tocopherol with ascorbic acid pretreated \& paracetamol treated group.

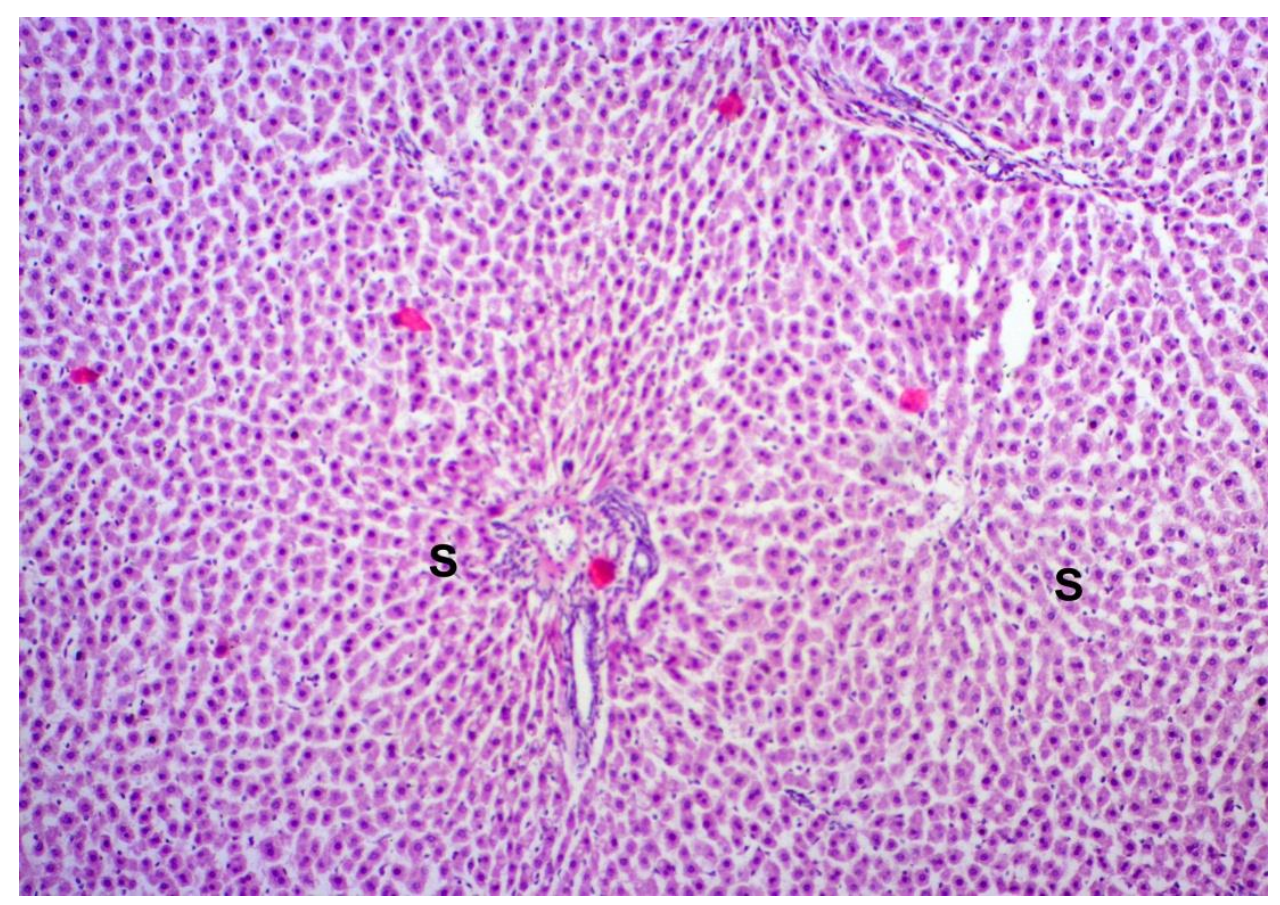

Figure 2: Architecture of liver of baseline control rats (here $S$ hepatic represents sinusoid in $X 100$ )

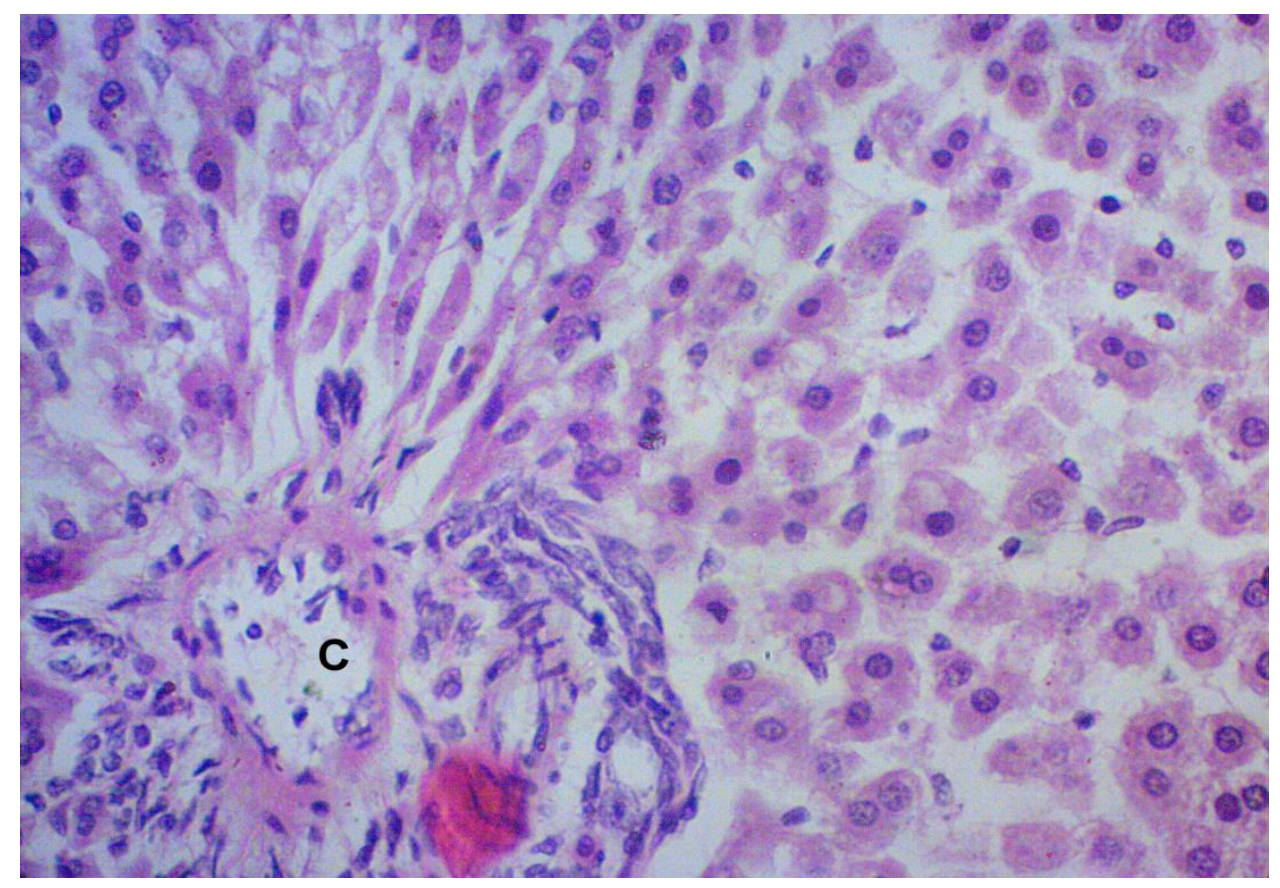

Figure 3: Architecture of liver of baseline control rats (here $C$ represents cental vein in X 400) 


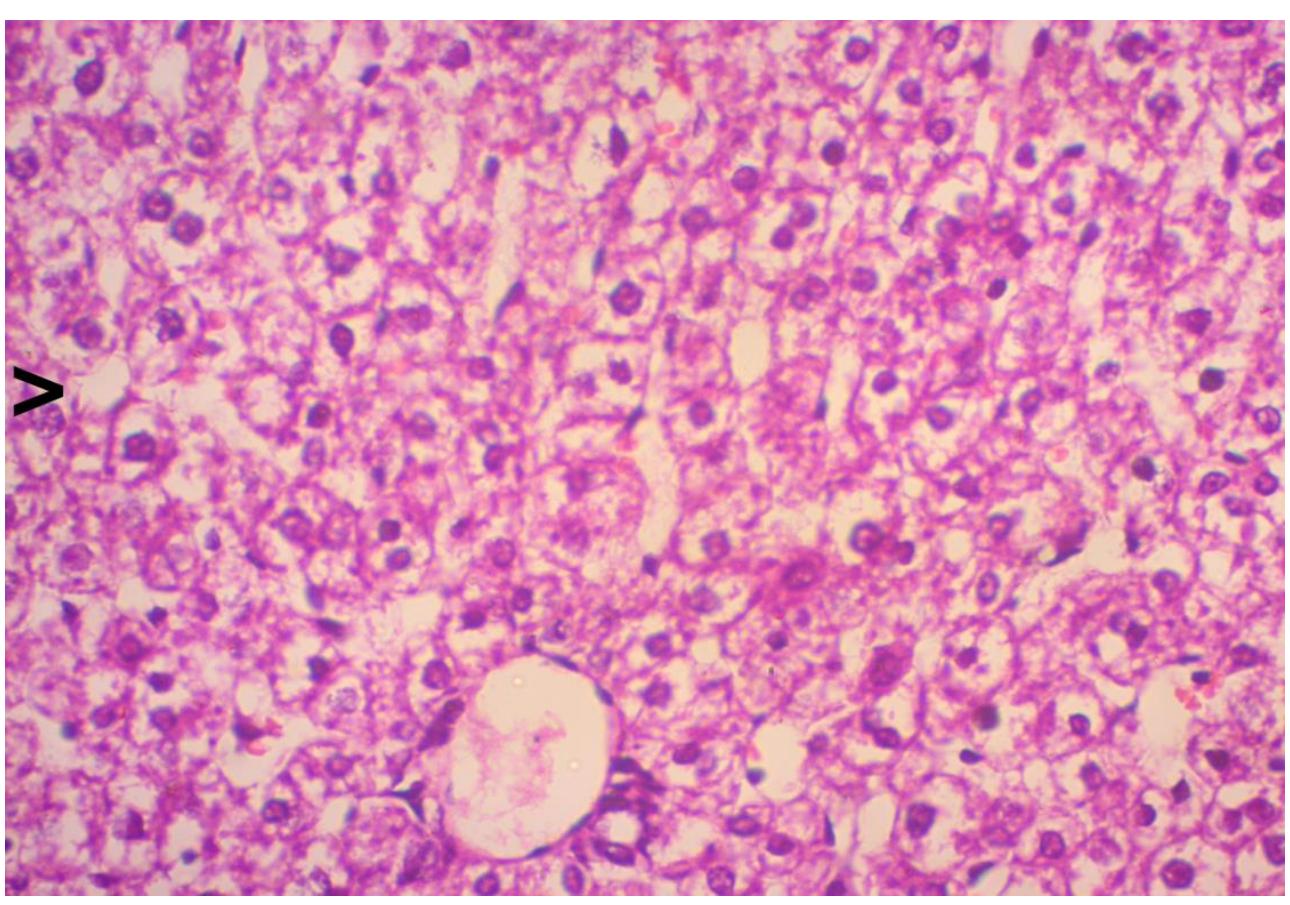

Figure 4: Liver of paracetamol treated rats (here arrow mark > represents ballooning degeneration in X 400)

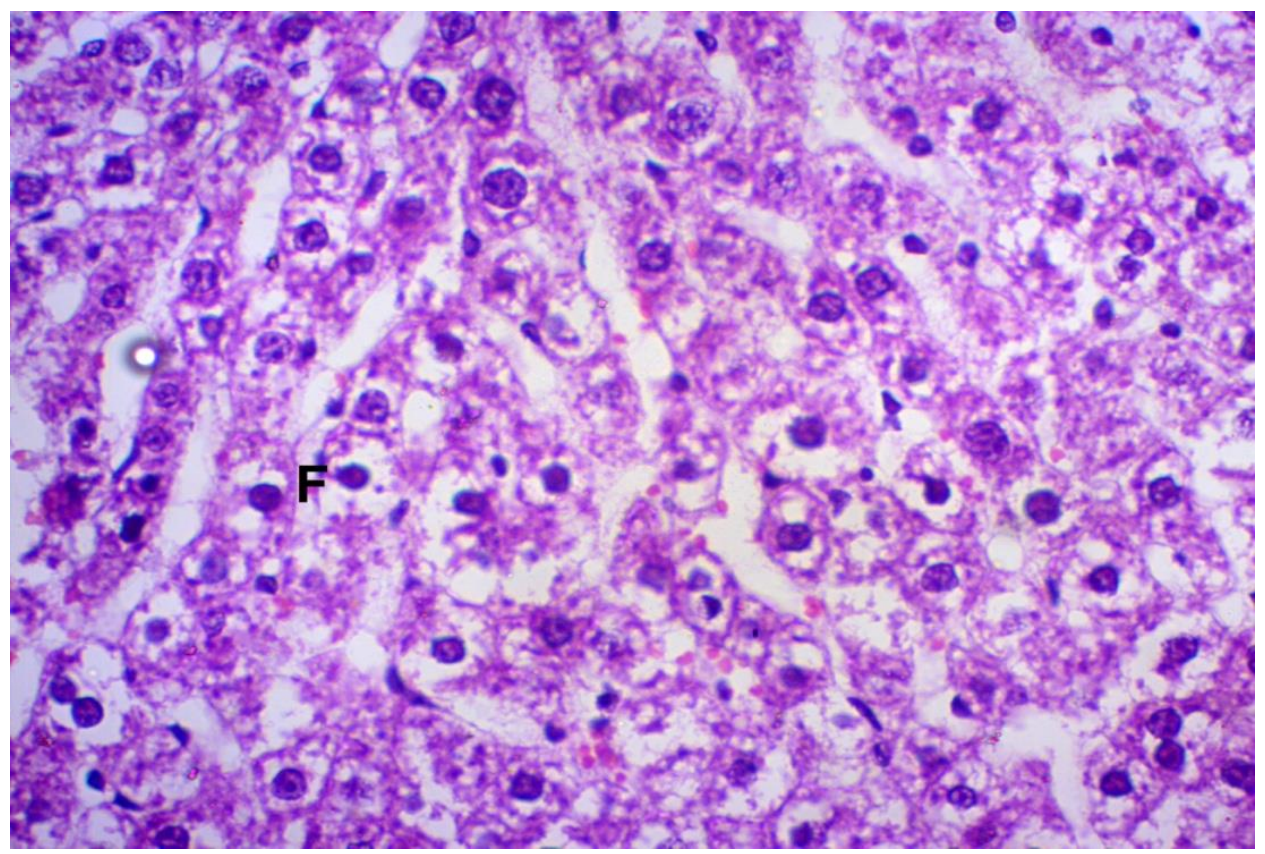

Figure 5: Liver of paracetamol treated rats (here $\mathrm{F}$ represents fatty changes of liver in $\mathrm{X} 400$ )

However, mild or no significant degenerative changes were observed in rats with $\alpha$-tocopherol pretreated and paracetamol treated group (Figure-6). Restoration of almost normal architecture was also showed in rats with ascorbic acid pretreated and paracetamol treated group rats (Figure-7). Moreover, combined $\alpha$-tocopherol plus ascorbic acid pretreated and paracetamol treated group exhibited no significant histological alteration compared to base line control group (Figure-8). 


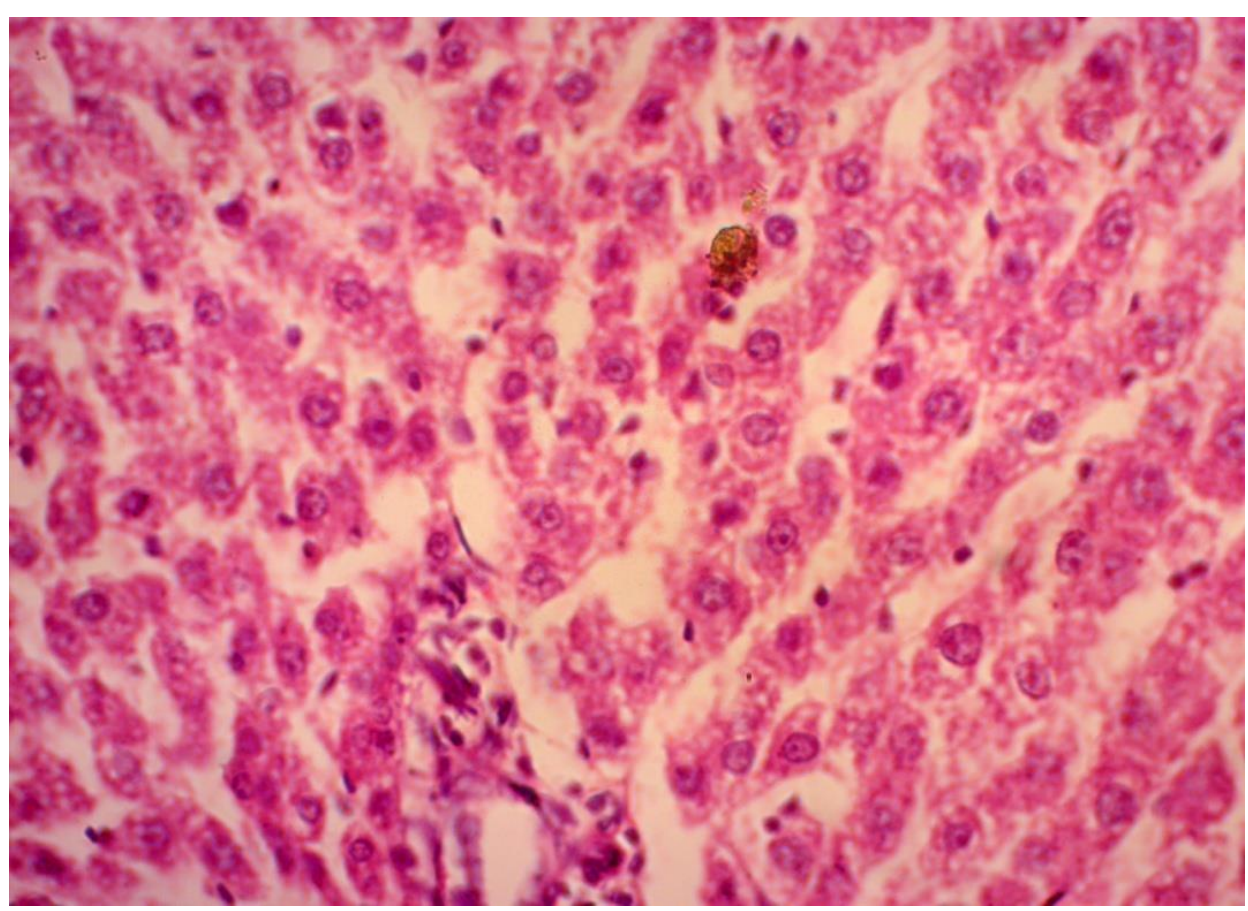

Figure 6: Improvement of necrosis and other changes of liver in $\alpha$-tocopherol pretreated and paracetamol treated rats $(X 400)$

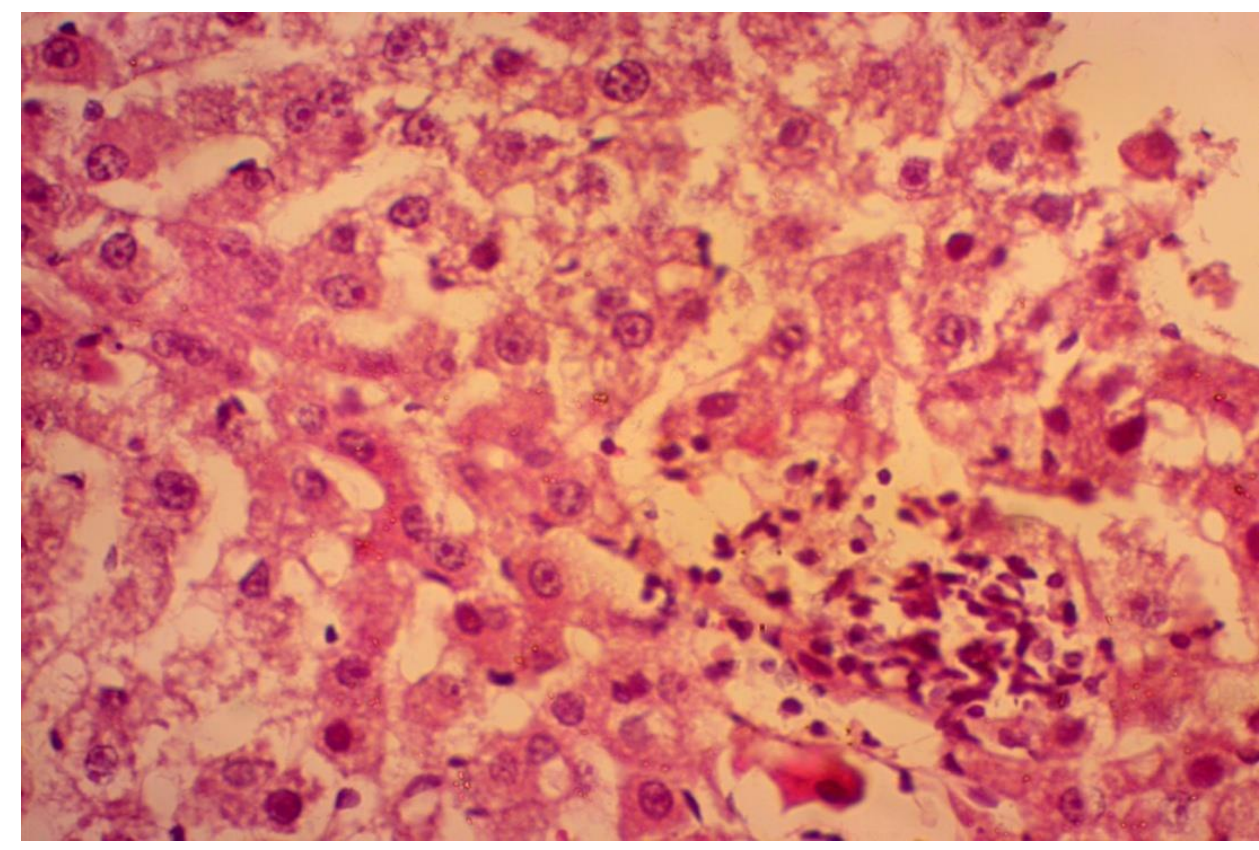

Figure 7: Improvement of necrosis and other changes of liver in ascorbic acid pretreated and paracetamol treated rat $(X 400)$ 


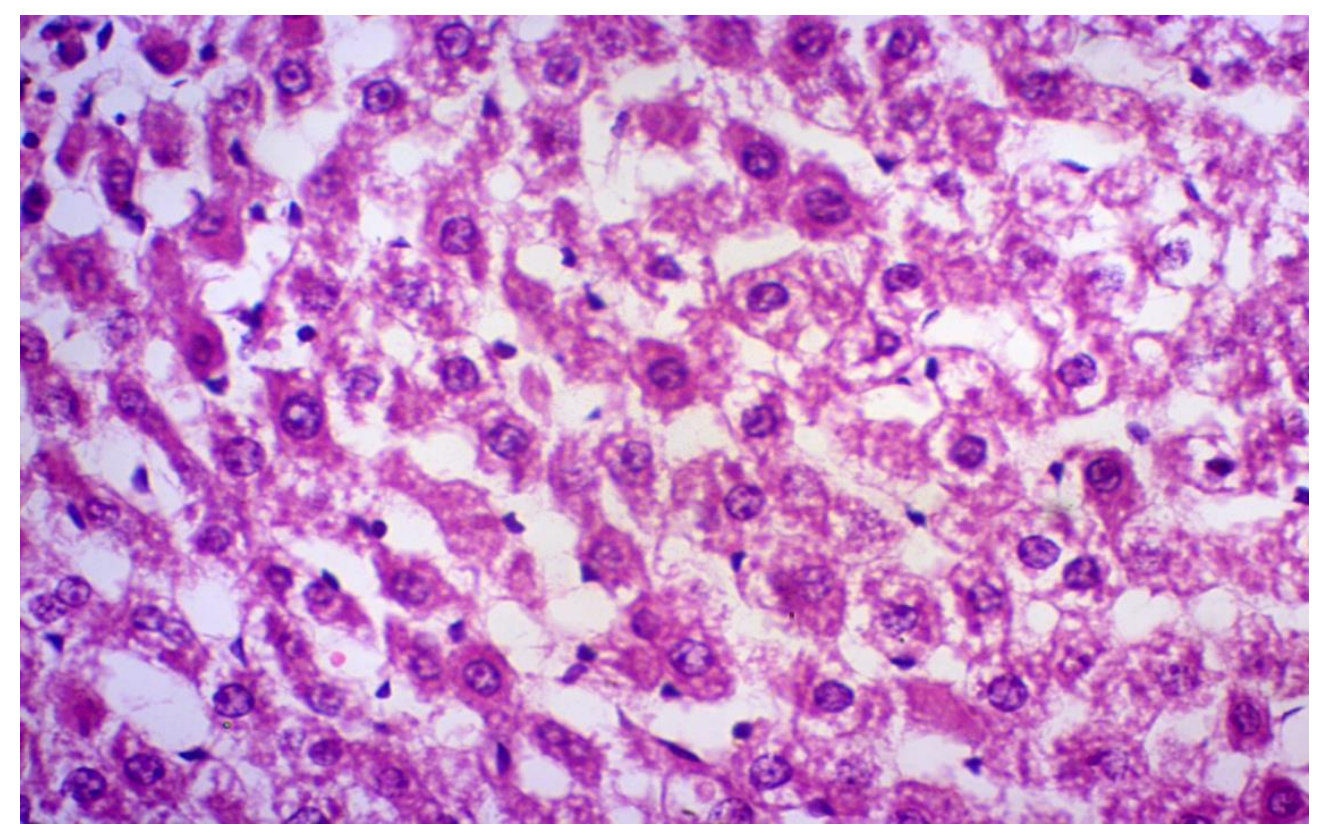

Figure 8: Improvement of necrosis and other changes of liver in combined $\alpha$-tocopherol with ascorbic acid pretreated and paracetamol treated rats (X 400)

\section{Discussion}

In this present study, increased levels of ALT may indicate the cellular leakage and damage of functional integrity of hepatocyte cell wall. This enzyme to leak out of the liver into the circulation due to hepatocellular leakage [31]. Serum levels of ALT were significantly increased in paracetamol treated group, $\alpha$-tocopherol pretreated \& paracetamol treated group, ascorbic acid pretreated \& paracetamol treated group than that of baseline control group. This finding was equivocal with that of some other investigators [8,32]. The ALT level of combined $\alpha$-tocopherol with ascorbic acid pretreated \& paracetamol treated group which was increased than that of baseline control group but the difference was not statistically significant. However, serum ALT levels of all the experimental groups were decreased in comparison to that of paracetamol treated control group but the difference was statistically significant. Similar findings was also observed by some investigators [30,33].

However, the MDA concentration in the liver tissue homogenate was significantly increased in paracetamol treated control group, ascorbic acid pretreated \& paracetamol treated group than that of baseline control group. Similar observation was made by some other researchers [34,35]. Whereas, the MDA concentration was increased in $\alpha$-tocopherol pretreated \& paracetamol treated group and 
also in combined $\alpha$-tocopherol with ascorbic acid pretreated \& paracetamol treated group than that of baseline control group but the difference was not statistically significant. Again the MDA concentration of all the experimental groups were significantly decreased in comparison to that of paracetamol treated control group. An almost similar finding was observed by other researchers $[36,37]$.

Moreover, abnormal histological changes, such as centrilobular necrosis, disorganization of hepatic sinusoids, infiltration of lymphocytes and Kupffer cells, fatty changes and ballooning degeneration were observed in $100 \%$ of rats in paracetamol treated control group. These findings were also in agreement with those of different investigators of other countries [38,39]. However, $70 \%$ rats from $\alpha$-tocopherol pretreated \& paracetamol treated control group, 50\% rats from ascorbic acid pretreated \& paracetamol treated group \& $80 \%$ rats from combined $\alpha$-tocopherol with ascorbic acid pretreated \& paracetamol treated group showed normal histological findings. There were statistically significant differences in histological findings of liver observed among paracetamol treated control group vs ascorbic acid pretreated \& paracetamol treated group. Again all the experimental groups showed better histological findings than that of paracetamol treated control group and the differences were statistically significant. Almost similar finding was also depicted by other researchers [27,32]. It is assumed that both $\alpha$-tocopherol \& ascorbic acid might be activated together after administration and synergistically acted to cause more effectiveness in hepatoprotective effects in the possible mechanisms (Figure S1 and Figure S2).

\section{Conclusions}

From this study, it can be concluded that the combined treatment of $\alpha$-tocopherol \& ascorbic acid have better hepatoprotective effects than $\alpha$-tocopherol or ascorbic acid alone against paracetamol induced liver damage in Wistar albino male rats. In addition, the decrement of free radicals produced by vitamin E could be a better hepatoprotective antioxidant than Vitamin C in paracetamol induced toxicity. Still we recommend further experimental study to elucidate the exact component and mechanism responsible for these effects. 


\section{Author Contributions:}

Conceptualization, S.I.K.; Methodology, S.I.K, M.B, R.C and M.M.R.; Formal Analysis, S.I.K, R.C and M.M.R.; Investigation, S.I.K, R.C and M.M.R.; Data Curation, S.I.K, R.C, M.A, and M.M.R.; Writing-Original Draft Preparation, S.I.K, M.A, and M.M.R.; Writing - Review and Editing, M.A, S.I.K, R.C and M.M.R.; Supervision, M.B.; All authors have read and agreed to the published version of the manuscript.

Funding: This research received no external funding

Acknowledgments: The authors would like to acknowledge Department of Physiology, Sir Salimullah Medical College, Dhaka, Bangladesh.

Conflicts of Interest: The authors declare no conflict of interest

\section{References}

1. Collier; D., J.; Webster; G. Liver and Biliary Tract Disease. In: Colledge R, Walker BR, Ian SR (eds). Davidson's Principles and Practice of Medicine., 22nd ed.; Churchill Livingstone: China, 2014:919-983.

2. Finlayson NDC; Hayes NC; Simpson KJ; Haslett C; Chilvers ER; J, H. In: Diseases of the liver and Biliary System. Davidson's Principle and Practice of Medicine, 18th ed.; Churchill Livingstone: China, 1999.

3. Lidofsky, S. Liver transplantation for fulminant hepatic failure. Gastroenterology clinics of North America 1993, 22, 257-269.

4. Kaplowitz, N. Drug-induced liver injury. Clinical infectious diseases 2004, 38, S44-S48.

5. Wai D. Drug induced liver diseases. In: Mahtab M, Rahman S. Liver a complete book on hepato-pancreato-biliary diseases., 1st ed.; Reed Elsevier: India, 2010.

6. Yoon, E.; Babar, A.; Choudhary, M.; Kutner, M.; Pyrsopoulos, N. Acetaminophen-Induced Hepatotoxicity: a Comprehensive Update. J Clin Transl Hepatol 2016, 4, 131-142, doi:10.14218/jcth.2015.00052.

7. Mirochnitchenko, O.; Weisbrot-Lefkowitz, M.; Reuhl, K.; Chen, L.; Yang, C.; Inouye, M. Acetaminophen toxicity opposite effects of two forms of glutathione peroxidase. Journal of Biological Chemistry 1999, 274, 10349-10355.

8. Ezeala, C.; Nweke, I.; Unekwe, P.; El-Safty, I.; Nwaegerue, E. Fresh garlic extract protects the liver against acetaminophen-induced toxicity. The Internet Journal of Nutrition and Wellness $2009,7$.

9. Rang HP; Dale HP; Ritter JM; PK, M. Harmful effects of drugs. In:Rang and Dale's pharmacology, 6th ed.; 2009; pp. 751-764.

10. Michael SL; Pumford NR; Mayeux PR; Niesman MR; JA, H. Pretreatment of mice with macrophage inactivators decreases acetaminophen hepatotoxicity and the formation of reactive oxygen and nitrogen species. In: Hepatology; 1999; Vol. 30th pp. 186-195.

11. Muriel, P. Role of free radicals in liver diseases. Hepatology international 2009, 3, 526-536.

12. Bijlani RL. Functions of the liver and their laboratory assessment. In: Understanding Medical physiology, 3rd ed.; Jaypee brothers medical publishers (P) ltd.: New Delhi, 2004; pp. 422429.

13. Al, S.A.-k.A.-S. PROTECTIVE EFFECT OF VITAMIN E ON ACETAMINOPHEN-INDUCED HYPERLIPIDEMIA IN FEMALE RABBITS. Iraqi Journal of Science 2011, 52, 300-305. 
14. Marcus R; AM, C. Fat-soluble vitamins: Vitamins A, E and K. In: Hardman JG, Limibird LE, (eds). Goodman and Gulman's The Pharmacological basis of Therapeutics, 11th ed.; McGraw Hill Co.: New York, 1996; pp. 1573-1590.

15. Burton, G.W.; Joyce, A.; Ingold, K.U. Is vitamin E the only lipid-soluble, chain-breaking antioxidant in human blood plasma and erythrocyte membranes? Arch Biochem Biophys 1983, 221, 281-290, doi:10.1016/0003-9861(83)90145-5.

16. KD, T. Miscellaneous drugs. In: Essentials of medical pharmacology, 7th ed.; 2013; pp. 911913.

17. Satayanarayana U; U, C. Chemical constituents of life. In: Biochemistry with Clinical Concepts \& case Study, 4th ed.; 2013; pp. 1-163.

18. Moreau, R.; Dabrowski, K. Body pool and synthesis of ascorbic acid in adult sea lamprey (Petromyzon marinus): an agnathan fish with gulonolactone oxidase activity. Proc Natl Acad Sci U S A 1998, 95, 10279-10282, doi:10.1073/pnas.95.17.10279.

19. García-Closas, R.; Berenguer, A.; Tormo, M.J.; Sánchez, M.J.; Quiros, J.R.; Navarro, C.; Arnaud, R.; Dorronsoro, M.; Chirlaque, M.D.; Barricarte, A. Dietary sources of vitamin C, vitamin E and specific carotenoids in Spain. British Journal of Nutrition 2004, 91, 1005-1011.

20. Guaiquil, V.H.; Vera, J.C.; Golde, D.W. Mechanism of vitamin C inhibition of cell death induced by oxidative stress in glutathione-depleted HL-60 cells. J Biol Chem 2001, 276, 4095540961, doi:10.1074/jbc.M106878200.

21. Ganesh, E.; Chowdhury, A.; Malarvani, T.; Ashok-vardhan, N. Hepatoprotective effect of Vitamin-E \& C in Albino rats. Int J Adv Lif Sci 2012, 3, 21-26.

22. Abbott, F.V.; Franklin, K.B.; Westbrook, R.F. The formalin test: scoring properties of the first and second phases of the pain response in rats. Pain 1995, 60, 91-102.

23. Tajik, H.; Tamaddonfard, E.; Hamzeh-Gooshchi, N. The effect of curcumin (active substance of turmeric) on the acetic acid-induced visceral nociception in rats. Pak J Biol Sci 2008, 11, 312-314.

24. Ali, T.; Javan, M.; Sonboli, A.; Semnanian, S. Evaluation of the antinociceptive and antiinflammatory effects of essential oil of Nepeta pogonosperma Jamzad et Assadi in rats. In Daru, 2012; Vol. 20, p. 48.

25. Abdulkhaleq, F.M.; Alhussainy, T.M.; Badr, M.M.; Khalil, A.A.A.; Gammoh, O.; Ghanim, B.Y.; Qinna, N.A. Antioxidative stress effects of vitamins C, E, and B12, and their combination can protect the liver against acetaminophen-induced hepatotoxicity in rats. In Drug Des Devel Ther, 2018; Vol. 12, pp. 3525-3533.

26. Selvam, N.T.; Venkatakrishnan, V.; Dhamodharan, R.; Murugesan, S.; Kumar, S.D. Hepatoprotective activity of methanolic extract of Syzygium jambos (Linn.) leaf against paracetamol intoxicated Wistar albino rats. In Ayu, 2013; Vol. 34, pp. 305-308.

27. Uchendu, I.; Agu, C.; Orji, O.; Nnedu, E.; Arinze, C.; Uchenna, A.; Okongwu, U. Effect of tomato (Lycopersicon Esculentum) extract on acetaminophen-induced acute hepatotoxicity in albino wistar rat. Bioequivalence and Bioavailability International Journal 2018, 2, 000119.

28. style="text-align:justify, p.c.M.; text-justify:inter-ideograph; SC., 1.-h.S. Paracetamol., 33 rd ed.; The Pharmaceutical Press: Great Britain., 2002; pp. 2679. 
29. Sumy, A.K.; Jahan, N.; Sultana, N.; Amin, S.R. Effect of Oyster Mushroom (Pleurotus Florida) on Paracetamol Induced Changes of serum bilirubin level and liver tissue protein in Rats. Journal of Bangladesh Society of Physiologist 2011, 6, 10-15.

30. Bashandy, S.A. Beneficial effect of combined administration of vitamin $\mathrm{C}$ and vitamin $\mathrm{E}$ in amelioration of chronic lead hepatotoxicity. The Egyptian Journal of Hospital Medicine 2006, 23, 371-384.

31. Duan, L.; Davis, J.S.; Woolbright, B.L.; Du, K.; Cahkraborty, M.; Weemhoff, J.; Jaeschke, H.; Bourdi, M. Differential susceptibility to acetaminophen-induced liver injury in sub-strains of C57BL/6 mice: 6N versus 6J. Food Chem Toxicol 2016, 98, 107-118, doi:10.1016/j.fct.2016.10.021.

32. Siahkoohi, S.; Anvari, M.; Akhavan Tafti, M.; Hosseini-sharifabad, M. The effects of vitamin E on the liver integrity of mice fed with acrylamide diet. Iranian Journal of Pathology 2014, 9, 89-98.

33. COŞKUN, Ö.; YAKAN, B.; ÖZTAŞ, E.; SEZEN, Ş.; GÜNAYDIN, A.A. Antioxidant and hepatoprotective activity of vitamin $\mathrm{E}$ and $\mathrm{EGb} 761$ in experimental endotoxemic rats. Turkish Journal of Medical Sciences 2000, 30, 427-432.

34. Al-Sayed, E.; Martiskainen, O.; Seif el-Din, S.H.; Sabra, A.N.; Hammam, O.A.; El-Lakkany, N.M.; Abdel-Daim, M.M. Hepatoprotective and antioxidant effect of Bauhinia hookeri extract against carbon tetrachloride-induced hepatotoxicity in mice and characterization of its bioactive compounds by HPLC-PDA-ESI-MS/MS. Biomed Res Int 2014, 2014, 245171, doi:10.1155/2014/245171.

35. Mohamad, N.E.; Yeap, S.K.; Lim, K.L.; Yusof, H.M.; Beh, B.K.; Tan, S.W.; Ho, W.Y.; Sharifuddin, S.A.; Jamaluddin, A.; Long, K., et al. Antioxidant effects of pineapple vinegar in reversing of paracetamol-induced liver damage in mice. Chin Med 2015, 10, 3, doi:10.1186/s13020-015-0030-4.

36. Knight, T.R.; Fariss, M.W.; Farhood, A.; Jaeschke, H. Role of lipid peroxidation as a mechanism of liver injury after acetaminophen overdose in mice. Toxicological sciences 2003, 76, 229-236.

37. Omotayo, M.A.; Ogundare, O.C.; Oluwafunmilayo, A.; Longe, S.A. Hepatoprotective effect of Mangifera-indica stem bark extracts on paracetamol-induced oxidative stress in albino rats. European Scientific Journal 2015, 11.

38. Shahid, M.; Subhan, F. Comparative histopathology of acetaminophen induced hepatotoxicity in animal models of mice and rats. Pharmacology Online 2014, 3, 32-43.

39. Ahmed, N.M.; Hamaad, F.A. Protective Effects of Açai in Combination with Vitamin C against Aluminum-Induced Toxicity in Rat Liver. Journal of Biology and Life Science 2018, 9, 1-16. 